\title{
DA PARTE AO TODO: A CISÃO CARTESIANA NA EPISTEMOLOGIA DE HEISENBERG
}

\author{
Vinícius Carvalho da Silva ${ }^{1}$ \\ Universidade do Estado do Rio de Janeiro (UERJ) \\ Universidade Federal do Tocantins (UFT) \\ https://orcid.org/0000-0002-1061-2727 \\ E-mail: carvalho.vinicius@mail.uft.edu.br
}

\section{RESUMO:}

Neste trabalho buscamos investigar como o físico filósofo alemão Werner Heisenberg compreendeu a importância da filosofia cartesiana na construção do pensamento científico da modernidade. Para Heisenberg o elemento central da grande influência de Descartes nas ciências da natureza é a separação entre "Deus", "homem" e "mundo". O físico filósofo analisa tal separação e propõe que a partir da mecânica quântica, a cisão entre sujeito e objeto, homem e natureza, tornou-se insustentável.

PALAVRAS - CHAVE: Teoria física; Epistemologia moderna; Mecânica quântica; Unidade da natureza; Física experimental.

\section{FROM PART TO THE WHOLE: THE CARTESIAN CISON IN HEISENBERG EPISTEMOLOGY}

\begin{abstract}
:
In this work we seek to investigate how the german physicist philosopher Werner Heisenberg understood the importance of cartesian philosophy in the construction of scientific thought of modernity. For Heisenberg, the central element of Descartes' great influence in the natural sciences is the separation of "God," "man," and "world." The physicist philosopher analyzes this separation and proposes that from quantum mechanics, the split between subject and object, man and nature, has become unsustainable.
\end{abstract}

KEY-WORDS: Physical theory; Modern epistemology; Quantum mechanics; Unity of nature; Experimental physics.

\footnotetext{
${ }^{1}$ Doutor em Filosofia da Ciência e Teoria do Conhecimento pela Universidade do Estado do Rio de Janeiro (UERJ), com estudos pela Universidade Federal do Rio de Janeiro (UFRJ), Rio de Janeiro - RJ, Brasil. Professor de Epistemologia e Teoria e História da Ciência na Universidade Federal do Tocantins (UFT), Palmas - TO, Brasil. Pós-doutorando em Saúde Pública pelo Instituto de Medicina Social da Universidade do Estado do Rio de Janeiro (UERJ), Rio de Janeiro - RJ, Brasil. Pesquisador do Instituto de Estudos Sociais e Conceituais de Ciência, Tecnologia e Sociedade.
}

SILVA, Vinícius Carvalho da. Da parte ao todo: a cisão cartesiana na epistemologia de Heisenberg. Griot : Revista de Filosofia, Amargosa - BA, v.18, n.2, p.1-13, dezembro, 2018. 
Neste trabalho não buscamos ressaltar uma relação entre os pensamentos do filósofo francês René Descartes e do físico filósofo alemão Werner Heisenberg. Nossa intenção não é propor convergências ou divergências, tampouco falamos da filosofia de Descartes, mas tão somente do Descartes de Heisenberg, isto é, de determinados elementos da filosofia cartesiana tal como compreendidos por Heisenberg.

Qual a importância que Heisenberg confere ao pensamento cartesiano no quadro da ciência moderna? De acordo com Heisenberg, Descartes exerceu papel capital na fundamentação filosófica da ciência natural de sua época. Assim o fez, tanto pelo seu mecanicismo que impregnou a cultura ocidental profundamente, quanto por sua defesa de um conhecimento rigoroso, analítico, construído laboriosamente por meio de um método criterioso e objetivo (HEISENBERG, W. 1987, p. 62). Descartes aparece como um pensador importante para as reflexões de Heisenberg na medida em que este se questiona se, no escopo da mais recente ciência natural, podemos coadunar o que ele chama de "cisões cartesianas" com os resultados da física subatômica. Se pensarmos a filosofia cartesiana e a mecânica quântica como sistemas de proposições, poderíamos compreender que tais sistemas são compatíveis? Todavia, devemos antes de tudo esclarecer o que Heisenberg entendia como sendo esta "cisão".

Há, no pensamento de Heisenberg, nitidamente, a noção de que a "cisão" empreendida por Descartes "moldou" o espírito ocidental, talvez como nenhuma outra filosofia moderna o fez. Qual é, entretanto, para Heisenberg, a peculiaridade desta cisão? Por que tal fato representa uma novidade na tradição filosófica, inaugurando um novo pensar distinto daquele dos antigos? De acordo com Heisenberg, Descartes estabelece uma "separação objetiva" entre "Deus", "mundo" e "homem" e, no caso deste último, entre seu corpo, sua extensão, a res extensa, e sua mente, sua substância pensante, a res cogitans ${ }^{2}$. Para Heisenberg, a sustentação tanto da cisão homem-mundo quanto da cisão entre res extensa e res cogitans não é possível no quadro atual da ciência natural:

A antiga divisão do universo num processo objetivo no espaço e no tempo, por um lado, e por outro lado, a alma, em que se reflete aquele processo, ou seja, a distinção cartesiana entre a res cogitans e a res extensa, não pode já servir como ponto de partida da ciência moderna. (...) A ciência já não é um espectador colocado em frente da natureza, mas reconhece-se a si mesma como parte da interação entre homem e natureza. O método científico, consistindo em abstrair, explicar e ordenar os fenômenos adquiriu consciência das limitações que lhe impõe o fato de a sua intervenção modificar e transformar o seu objeto a tal ponto que o método não pode separar-se do objeto. A imagem científica do universo deixa assim de ser uma verdadeira imagem da natureza. (HEISENBERG. 1995, p.28)

Como vimos, Heisenberg defende a noção de que, dado o desenvolvimento da

\footnotetext{
2 A distinção entre res cogitans e res extensa é proposta por Descartes em diversas passagens, como na quarta parte do Discurso do Método, e nas Meditações, na Meditação Segunda, quando ele trata do espírito humano e de seu conhecimento, e nas Respostas do autor às segundas objeções, no tópico das Razões que comprovariam a existência de Deus, e da distinção entre o espírito e o corpo humano. Ver: DESCARTES, R. Coleção Os Pensadores. J. Guinsburg e Bento Prado Júnior (Trad.). São Paulo Editora Nova Cultural, 1996.
} 
ciência natural, não nos é mais possível pensar o "eu" e o "mundo", sujeito e objeto, a parte e o todo, como entes isolados e independentes. Isto, se verdadeiro, parece nos impedir de adotarmos o realismo como filosofia geral, posto que não podemos considerar o mundo completamente isolado do sujeito que o investiga, e dos métodos que emprega para tal. Claro que poderemos, ainda, considerar Heisenberg um realista, desde que admitamos que a separação entre o sujeito do conhecimento e o mundo não é um pressuposto metafísico fundamental do realismo, e desde que, também, expandamos nossa noção de realidade. A realidade não é somente aquilo que existe de modo objetivo, independente de nós, mas a totalidade do ser, incluindo a imbricação entre o sujeito do conhecimento e o mundo físico do qual faz parte. De fato não é incomum que Heisenberg seja considerado realista por importantes filósofos contemporâneos. Em sua obra Por que os físicos acreditam que as coisas existem, Antonio Augusto Passos Videira considera que Heisenberg assumiu um "realismo desubstancializado", no qual a noção de corpo material, partícula elementar, perde sua importância ontológica ${ }^{3}$.

Para Heisenberg não seria adequada uma filosofia da ciência que pensa os procedimentos de experimentação como investigações neutras acerca de sistemas objetivos - todo processo de mensuração estabelece uma síntese inescapável entre os sujeitos que observam e os sistemas observados. Para Heisenberg, portanto, "eu" e "mundo" não podem ser separados no escopo da física contemporânea, como dito em Física e Filosofia:

\begin{abstract}
A antiga filosofia grega tentara achar uma ordem, na infinita variedade de coisas e fenômenos, pela procura de algum princípio fundamental de unificação. Já Descartes procurou estabelecer a ordem por meio de uma divisão (i.e., separação) fundamental. Todavia, as três partes que resultam dessa divisão perdem algo de sua natureza se cada qual for considerada separadamente das demais. Se quisermos mesmo fazer uso dos conceitos fundamentais cartesianos é essencial que Deus se encontre no mundo e no "Eu", e é também essencial que o "Eu" não possa ser realmente separado do mundo. (HEISENBERG. 1987, p.62,63)
\end{abstract}

Em outra passagem desta mesma obra, Heisenberg acena para o fato de que a divisão entre res cogitans e res extensa proposta por Descartes não representa o auge, a convicção final, do pensamento cartesiano. Heisenberg propõe que Descartes sabia da necessidade da síntese entre "corpo" e "mente", que não a ignorou, muito embora seja igualmente verdadeiro que, a despeito disto, foi a ideia da cisão, e não da síntese, que entrou para a história e influiu de modo decisivo na formação do caráter intelectual da

\footnotetext{
3 VIDEIRA, A. A. P. Por que os físicos acreditam que as coisas existem? Breves comentários a respeito das relações entre ciência e metafísica. Braga: Axioma , 2017. Em outra oportunidade (*ver abaixo) chamei a filosofia da mecânica quântica de Heisenberg de antirrealista, no sentido em que Heisenberg considera que o corpo material, da partícula elementar da física de partículas, não pode ser considerada como o fundamento último do real. $O$ próprio Heisenberg propõe que sua filosofia estaria muito próxima do idealismo de Platão. No entanto, penso, assim como Videira, que Heisenberg pode ser considerado um realista, embora não de substância, ou seja, não um realista materialista, mas um "realista desubstancializado", ou, um "realista nomológico" ou "realista matemático", que acredita na realidade ideal das simetrias matemáticas como fundamento ontológico do mundo. * SILVA, V. C. O anti-realismo na filosofia da física de Werner Heisenberg: da potentia aristotélica ao formalismo puro. Griot: Revista de Filosofia, v. 3,n2, p. 109-120, 2011.
} 
ciência moderna. É o legado desta cisão, e não propriamente Descartes, que Heisenberg pretende criticar:

Descartes, certamente, sabia da inegável necessidade dessa ligação, mas a filosofia e ciência natural no período seguinte desenvolveram-se com base na polaridade entre res cogitans ("coisa pensante") e res extensa ("coisa extensa"), a ciência natural concentrando seu interesse na "coisa extensa". A influência da divisão cartesiana sobre o pensamento humano, nos séculos que se seguiram, dificilmente poderá ser exagerada, mas é justamente essa divisão que teremos de criticar, mais adiante, do atual ponto de vista da física. (HEISENBERG. 1987, p.63)

Embora Descartes tenha promovido, em sua fisiologia, ou medicina, uma tentativa de síntese entre res extensa e res cogitans, a cisão que nos interessa ressaltar, entre homem e mundo, permaneceu. Tal cisão deve ser apontada como um dos fundamentos filosóficos da ciência moderna, posto que esta pressupõe que é possível compreender e explicar o funcionamento geral da natureza sem a necessidade de considerarmos tanto os observadores quanto a existência de Deus como relevantes. É interessante frisar que a não consideração da existência de Deus como elemento heurístico necessário para a formulação de uma ciência natural não implica a negação de sua existência, mas tão somente a irrelevância desta existência para a elaboração do sistema em questão, da mesma forma que, muito embora nos seja inegável nossa própria existência, também ela é considerada irrelevante para o entendimento da natureza pelo pensamento científico moderno. Heisenberg ressalta o caráter aparentemente necessário da cisão cartesiana para a ciência moderna afirmando que:

(...) essa divisão foi, durante muitos séculos, bem recebida. A mecânica de Newton, assim como todas as outras partes da física clássica, construídas segundo o modelo daquela mecânica, tiveram como ponto de partida a hipótese de que se pode descrever o mundo sem fazer qualquer menção a Deus ou a nós mesmos. Essa possibilidade logo pareceu necessária para a ciência natural em geral. (HEISENBERG, W. 1987, p.64)

De acordo com Heisenberg, "não poderia ter ocorrido a Descartes" o inexorável entrelaçamento entre o homem e a natureza. Séculos depois de Descartes, a ciência necessitaria de abandonar sua filosofia para continuar avançando e, de modo muito irônico, o apego de "cientistas renomados" às estruturas tradicionais de pensamento, cujos alicerces encontram-se fincados na cisão cartesiana, revelou-se como uma forma de resistência destes cientistas às mudanças científicas inescapáveis implicadas pelo avanço da ciência natural:

A ciência natural não se restringe simplesmente a descrever e explicar a Natureza; ela resulta da interação entre nós mesmos e a natureza, e propicia uma descrição que é revelada pelo nosso método de questionar. Essa foi uma possibilidade que não poderia ter ocorrido a Descartes, mas que torna impossível uma separação bem nítida entre o mundo e o "Eu". (...) Se observarmos a dificuldade que mesmo cientistas eminentes, como Einstein, tiveram em entender e aceitar a interpretação de Copenhagen da teoria quântica iremos encontrar, na raiz dessa dificuldade, a divisão cartesiana.

SILVA, Vinícius Carvalho da. Da parte ao todo: a cisão cartesiana na epistemologia de Heisenberg. Griot : Revista de Filosofia, Amargosa - BA, v.18, n.2, p.1-13, dezembro, 2018. 
(HEISENBERG, W. 1987, p.64)

Mas por que "homem" e "natureza", de acordo com Heisenberg são de tal modo entrelaçados, que não podemos mais sustentar a cisão cartesiana? Em que medida, e fundamentados em quais constatações, podemos afirmar que não é possível isolarmos "homem" e "natureza", e à moda dos modernos, fazermos uma ciência que exclua os observadores da descrição objetiva dos sistemas observados? Não somente para Heisenberg, mas para a Interpretação de Copenhagen, da qual Heisenberg foi um dos mais importantes proponentes, uma das proposições fundamentais da mecânica quântica pode ser assim formulada: "Nenhum evento subatômico pode ser descrito sem fazer referência aos meios pelos quais foi observado". Observar $x$ implica perturbar $x$ por meio de algum procedimento de mensuração, de tal modo que nunca observamos $x$ como $x$ é in natura, independente de nós, mas somente como $x$ interage conosco. Os enunciados científicos experimentais nada comunicam sobre o mundo, as coisas. São enunciados restritos ao comportamento da natureza durante os eventos de interação entre os sistemas observados e os arranjos experimentais de observação. Para Bohr:

A elucidação dos paradoxos da física atômica revelou o fato de que a inevitável interação dos objetos e dos instrumentos de medida instaura um limite absoluto à possibilidade de falarmos de um comportamento dos objetos atômicos que independa dos meios de observação. (...) Estamos diante de um problema epistemológico bastante novo na filosofia natural. (BOHR.1995, p. 32)

De acordo com Bohr, portanto, há a impossibilidade de descrevermos objetivamente o mundo sem fazermos referência ao sistema experimental por meio do qual são coletadas, por observação, as informações acerca de seus eventos e estruturas. Nas palavras de Paulo de Tarso Gomes:

Na mecânica quântica, o sujeito e os instrumentos de medição passam a fazer parte do experimento, isto é, influem em seu resultado revelando assim o entrelaçamento entre sujeito e mundo. Antes da medição, o que chamamos de realidade é apenas uma probabilidade. Depois da medição, o resultado não é uma medida determinada ou um fato, mas a probabilidade de uma medida, ou a probabilidade de ocorrência de um fato" (GOMES. 2007, p. 79).

Contudo, ao elaborarem esta noção, não significa que os físicos filósofos de Copenhagen tenham admitido a entrada de elementos subjetivos (ou "subjetivistas") na mecânica quântica. Aqui, não se trata de nenhuma forma de psiquismo ou mentalismo, de nenhum tipo de idealismo místico. Heisenberg, e Bohr, não estão dizendo que a mente do observador interfere no experimento, que o pensamento do observador interage com a matéria. A vindicação é outra não é possível descrever o resultado do experimento sem levar em conta todo o sistema experimental, e não é possível calcular com exatidão o quanto o método de observação impactou os eventos observados. Se fosse possível saber exatamente o quantum de perturbação, 
poderíamos subtraí-lo do resultado final, e chegarmos a uma representação verossímil de como deve se comportar o sistema observado nos intervalos entre as observações. Todavia, tais físicos filósofos consideraram que a interação entre sujeito e objeto é tão intrínseca, que abstrair o sujeito (arranjo experimental, método de observação, análise do resultado, interpretação do resultado) da equação final não é uma possibilidade.

A interação entre o sujeito que observa e o sistema objetivo que é observado é ela mesma objetiva - ou seja, o resultado desta interação não depende das condições psicológicas do observador. Mesmo assim, e para todos os casos, continua a vigorar a impossibilidade de falarmos de um comportamento dos objetos atômicos sem fazermos referências aos meios de observação. Portanto, já não é possível qualquer sistema científico que vise explicar o funcionamento geral da natureza sem levar em conta o entrelaçamento entre observador e natureza - tudo se passa, deste modo, como se a ciência nunca falasse diretamente da natureza, mas tão somente das interações entre natureza e homem". Bohr referia-se ao caráter fundamental destas "interações", que definiriam o objeto último de quaisquer ciências, como "uma inseparabilidade entre conteúdo objetivo e sujeito observador" (BOHR.1995, p. 38).

A convicção de que a cisão cartesiana não poderia ser sustentada no quadro geral da física subatômica, que se desenvolvia a plenos pulmões na primeira metade do século XX, não se restringe aos físicos filósofos da Interpretação de Copenhagen. Embora, na visão de Heisenberg, grandes nomes, como Einstein, permanecessem fiéis aos ditames da tradição, podemos notar que mesmo entre cientistas que em linhas gerais discordavam dos partidários de Copenhagen, a divisão proposta por Descartes deixara de ser uma noção fundamental para a física. Erwin Schröndiger, por exemplo, dava tal cisão como algo obscuro, não resolvido:

Nem sequer é absolutamente claro o que significa esta antítese entre a natureza objetiva e a mente humana. Porque, por um lado, faço indubitavelmente parte da Natureza, ao passo que, por outro lado, para mim a natureza objetiva é apenas um fenômeno da minha mente. (SCHRÖDINGER. 1996, p. 130)

Schrödinger considerava que tal questão, embora não resolvida, era intrínseca à prática científica:

Desde essa época [gregos antigos] a questão surgiu sempre que existiu ciência, de tal forma que a poderíamos detectar ao longo dos séculos, falando das atitudes de Descartes, Leibniz, ou Kant relativamente a ela (SCHRÖDINGER. 1996, p. 133).

Schrödinger, todavia, era um opositor da Interpretação de Copenhagen, e buscou formular uma interpretação diferente. Na interpretação de Copenhagen, não

\footnotetext{
${ }^{4}$ Em minha dissertação de mestrado pesquisei as influências da filosofia kantiana nesta forma de pensar. A ideia de que "a coisa em si" não pode ser conhecida, mas somente o modo como ela aparece, notadamente, parece ser uma das implicações do pensamento filosófico de Heisenberg. Ver: SILVA, Vinícius Carvalho. A interpretação filosófica da mecânica quântica de Werner Heisenberg: Ontologia matemática e crise nos fundamentos da lógica clássica. Dissertação de Mestrado. Rio de Janeiro: Universidade do Estado do Rio de Janeiro, 2012.
} 
faz sentido falar que uma partícula $p$ existe sem fazer referência ao processo de observação de $p$. Já Schrödinger busca enfatizar que, se $p$ existe, então este é o caso independente de $p$ ser observada ou não.

\begin{abstract}
Afirmo que é possível a seguinte interpretação: existe um objeto físico completamente determinado, mas nunca poderei saber tudo acerca dele. No entanto, esta interpretação revelaria uma incompreensão total do que Bohr e Heisenberg, e aqueles que os seguiram, efetivamente pretendem afirmar. $\mathrm{O}$ que eles querem dizer é que o objeto não tem qualquer existência independente do sujeito que observa. $O$ que eles querem dizer é que as descobertas recentes na física fizeram avançar o limite misterioso entre o sujeito e o objeto, e assim se verificou que esse limite já não era, de todo, um limite preciso. (SCHRÖDINGER. 1996, p. 131)
\end{abstract}

Mas qual era, enfim, a posição de Schrödinger neste tópico? O que o justificava a não coadunar com Heisenberg? Sabemos por meio de seus escritos em Ciência e Humanismo que, apesar de suas objeções, Schrödinger admitia a importância da ênfase que Heisenberg e Bohr davam às "interações" entre sujeitos e objetos na física contemporânea. Entretanto, o criador da mecânica ondulatória mantinha-se cético quanto à participação da ciência na elucidação das questões filosóficas fundamentais. Para ele, embora a ciência fosse parte do empreendimento filosófico, participando como elemento ativo na busca pela solução da questão filosófica antiga "Quem somos nós?", a relação sujeito-objeto não poderia ser resolvida pelas investigações científicas puramente técnicas, - muito embora admitisse que não soubesse ao certo por que:

Mas, apesar de tudo isso, não posso acreditar (e esta é minha primeira
objeção) que a investigação filosófica mais profunda relativa à relação entre
sujeito e objeto, e relativa ao verdadeiro significado da distinção entre
ambos, dependa dos resultados quantitativos das medições físicas e químicas
com balanças, espectroscópios, microscópios, telescópios, contadores Geiger-
Müller, câmaras de nevoeiro de Wilson, placas fotográficas, disposições para
medir a queda da radioatividade e tudo o mais. Não é muito fácil dizer por
que é que não acredito. Sinto que existe certa incongruência entre os meios
aplicados e o problema a resolver. (SCHRÖDINGER. 1996, p. 132)

Parece-me, contudo, que se dirigidas a Heisenberg, tais críticas não alcançaram o alvo. Se Heisenberg se dispõe a analisar a complexa e intrincada relação sujeitoobjeto no escopo da física de sua época, ele o faz, não por lançar mão de complexas parafernálias tecnológicas, o instrumental de mensuração, comum em laboratório de pesquisas físicas. Heisenberg, como cientista, se lida com este estado de coisas, é antes de tudo um físico teórico, dado às maiores abstrações, tanto que sua mecânica matricial para sistemas subatômicos foi mal aceita pela maior parte dos físicos de então, por parecer-lhes excessivamente formal, sem laços sólidos com a experiência, muito embora, e para desagradável surpresa de todos, tenha se mostrado tão correta e bem sucedida quanto a mecânica ondulatória desenvolvida por Schrödinger, sendo-lhe matematicamente equivalente, e formando, junto com esta, os fundamentos da mecânica quântica. Se Heisenberg, portanto, pensa tal questão, não o faz sem lançar mão de sofisticadas reflexões filosóficas, não se limitando a tentar desvendar o 
mistério por meio de aparelhagens de laboratório - Parece-me, portanto, que Heisenberg compreendia que os laboratórios e seus instrumentos são apenas expressões e extensões do pensamento humano.

A noção de "inseparabilidade entre conteúdo objetivo e sujeito observador" presente na Interpretação de Copenhagen, embora polêmica, como vimos, propagouse, e foi compartilhada por muitos cientistas e filósofos da ciência, como Gaston Bachelard: "Em microfísica nunca se tem a certeza de experimentar 'um' elemento isolado pelo simples fato de que não há meios para reconhecer o objeto isolado" (BACHELARD. 2010, p. 25). Bachelard está a defender que não podemos "isolar" elétrons e demais objetos subatômicos como indivíduos, posto que (i) todo objeto microfísico pode ser entendido somente como parte inseparável da classe destes objetos mesmos e (ii) todos os objetos são absolutamente isomórficos, de tal modo que não há nada em um elétron, p.ex., que lhe garanta individualidade em face de outro. Por outro lado, é perfeitamente consonante com o pensamento de Bachelard afirmar que não podemos "isolar" o objeto microfisíco do sujeito macrofísico que empreende sua mensuração. Sendo assim, sujeito e objeto formam um sistema físico não fragmentável, o oposto do que propõe o sistema cartesiano.

A "interação" entre homem e natureza na configuração daquilo que chamamos de realidade parece, portanto, ser uma característica fundamental da natureza. 0 homem não somente é uma criatura da natureza, pois, de certa forma, dela também é criador, na medida em que, com ela interagindo, concorre para recriá-la de modo peculiar. Como podemos descrever, entretanto, a natureza desta inseparabilidade sujeito-mundo? Qual o papel dos procedimentos de observação nesta "interação"? A resposta de Heisenberg a tal pergunta revelar-se-á bastante original e, sobretudo, forte. Heisenberg propõe que não existe uma única realidade objetiva, mas uma trama de realidades potenciais superpostas formando sistemas quânticos concomitantes que existem como "possibilidades" dadas pelas leis da natureza em escala quântica. Mas como experimentamos uma única realidade clássica macrofísica? Isto ocorre porque nós, sistemas físicos complexos, somos permanentes eventos de observação - estarmos no mundo é interagirmos com ele. Ocorre que são justamente os processos de observação que selecionam, entre todas as realidades potenciais, a realidade física factual. Em termos técnicos, quando ocorre um evento de observação, a interação entre o sistema observador e a natureza observada promove o colapso de todas as realidades potenciais, menos uma, justamente a que experimentamos como sendo a única realidade objetiva, simplesmente porque, de todas as realidades superpostas, foi a única que se realizou, "saltando" do status de possibilidade para o de "mundo físico":

$O$ ato de observação, por si mesmo, muda a função de probabilidade de maneira descontínua; ele seleciona, entre todos os eventos possíveis, o evento real que ocorreu. Visto que, pela observação, nosso conhecimento do sistema mudou descontinuamente, sua representação matemática também sofreu esta descontinuidade. (HEISENBERG. 1987, p. 46)

Neste ponto do pensamento de Heisenberg, uma "grave" noção pode estar implicada: $O$ que está posto, o mundo, é configurado, de certo mundo, pela interação entre os sistemas observados e os processos de observação. Heisenberg defende, em 
Física e Filosofia, no capítulo "A Interpretação de Copenhagen da Teoria Quântica" que "a transição do "possível' ao "real' ocorre durante o ato de observação" (HEISENBERG. 1996, p. 46). Todavia, Heisenberg desacredita que seja a "consciência" que promova o colapso da função de probabilidade. Para o físicofilósofo, a "interação" que promove a transição do "possível" ao "real" não é entre mente e matéria, mas entre sistemas macro e microfísicos:

Aquele termo diz respeito à componente física do ato de observação, mas não à psíquica e poderemos dizer que a transição do "possível" ao "real" toma lugar tão logo a interação do objeto com o instrumento de medida (e, portanto, com o resto do mundo) tenha se realizado; ele nada tem a ver com o ato de registrar o resultado por parte da mente do observador. (HEISENBERG. 1987, p. 46)

Entretanto, o elemento psíquico não é de todo banido da teoria, permanecendo como uma noção fundamental, em certo sentido. Se não é a interação entre mente e matéria que promove a transição do "possível" ao "real", mas sim a interação do objeto com o instrumento de medida, a mente permanece inescapavelmente como elemento lógico necessário nesta cadeia de raciocínios, uma vez que se revela como a pré-condição para a existência de quaisquer instrumentos de medida - não poderia haver ato de observação objetiva no mundo se não houvesse um fenômeno mental elementar e fundamental: a interpretação dos resultados das observações. A atividade consciente, portanto, é pré-condição de qualquer evento de observação. Na mecânica quântica, de acordo com Heisenberg, os observadores devem sempre ser levados em conta, porque os eventos de observação influenciam o modo de ser dos sistemas observados, e porque quaisquer eventos de observação pressupõem atividades conscientes:

Isso de novo realça o elemento subjetivo na descrição dos eventos atômicos, pois o instrumento de medida foi construído pelo observador, e temos que nos lembrar que aquilo que observamos não é a Natureza em si, mas sim a Natureza exposta ao nosso método de questionar. (HEISENBERG. 1987, p. 48)

O que "Copenhagen" afirma, portanto, é que o ato de observação, isto é, a interação entre os instrumentos de medida e os objetos observados constitui o processo por meio do qual a soma das possibilidades se converte na realidade objetiva. Todavia, "entre" observações, os sistemas observados voltam ao estado potencial, no qual todas as realidades quanticamente possíveis estão superpostas:

Se quisermos descrever o que ocorre em um evento atômico, deveremos compreender que o termo 'ocorre' pode somente ser aplicado à observação, e não ao estado de coisas durante duas observações consecutivas (HEISENBERG, 1987, p. 46).

Parece, portanto, que, strictu sensu, a Interpretação de Copenhagen defende que (i) a realidade, embora forme um todo complementar, possui gradações nomológicas próprias de cada escala espacial, de modo que no nível quântico as leis da 
natureza são tais que o universo, nesta escala, é a soma de todos os seus estados quânticos possíveis, (ii) quando a matéria se aglomera formando estruturas complexas que transcendem, geometricamente, os limites do mundo quântico, o alcance das leis quânticas vai diminuindo na mesma proporção que tais estruturas vão aumentando, até que, para objetos macroscópicos, as leis da mecânica clássica revelam-se como um caso limite das leis da mecânica quântica.

De acordo com esse processo, uma estrutura material complexa macroscópica é demasiado "pesada" para ser afetada pelas leis quânticas, e muito embora as partículas subatômicas das quais é composta existam de modo superposto como a soma de todos os seus estados quanticamente possíveis, a soma de todas as suas partes, o que resulta em algo macroscópico, existe como apenas "um" objeto clássico, embora sempre haverá uma probabilidade maior que zero de que objetos clássicos experimentem, mesmo sutilmente, estados de superposição.

De acordo com a Interpretação de Copenhagen, portanto, como sistemas físicos complexos que somos, não experimentamos os efeitos quânticos tão comuns naquele nível. Neste exato momento, portanto, existimos de dois modos: (i) enquanto "soma" de todas as partículas que nos compõem, somos um "corpo" macroscópico, experimentando uma existência "clássica" no espaço-tempo, (ii) entretanto, cada uma das partículas que nos compõe experimenta existência quântica, existindo de modo superposto, como soma de todos seus estados quanticamente possíveis. A existência no nível quântico é apenas uma função de probabilidade - e como existem vários estados prováveis para cada objeto, cada objeto é, portanto, a soma de todas estas probabilidades. Cada objeto, antes de ser uma "coisa" material, e mais do que uma onda de matéria, é uma onda de probabilidades. Neste sentido, o conceito de probabilidade em mecânica quântica não deve ser confundido com o conceito clássico de probabilidade:

\begin{abstract}
Nosso uso de termos probabilísticos para descrever o produto de eventos do quotidiano reflete, portanto, não a natureza intrínseca do processo, mas apenas nossa ignorância sobre certos aspectos dele. As probabilidades nas teorias quânticas são diferentes. Elas refletem uma aleatoriedade fundamental da natureza. $O$ modelo quântico da natureza incorpora princípios que contradizem não só a experiência diária, mas também nossa concepção intuitiva de realidade. (HAWKING; MLODINOW. 2001, p. 55)
\end{abstract}

Uma vez que a probabilidade, em mecânica quântica, é uma característica da natureza, e que a efetivação de um dos estados previstos pelo probabilismo quântico como realidade objetiva por meio de um ato de observação representa a inseparabilidade entre os sujeitos e os objetos da observação, e, portanto, entre homem e mundo, Heisenberg defende que a cisão cartesiana não pode ser coadunada com o mais recente desenvolvimento desta área de pesquisa da ciência natural. Para Bohr, a superação da divisão cartesiana se deve à "impossibilidade de qualquer separação nítida entre o comportamento dos objetos atômicos e a interação com os instrumentos de medida que servem para definir as condições em que os fenômenos aparecem" (BOHR. 1995, p. 51).

Se no sistema de Descartes, como Heisenberg compreendeu, somos 
observadores imparciais de um mundo mecânico independente e objetivo, na teoria quântica do físico filósofo não podemos falar de um mundo objetivo, dispensando a relação entre os observadores e o mundo. Tanto o mecanicismo de Descartes quanto o determinismo de Laplace são abandonados, uma vez que, não havendo a cisão proposta por Descartes, não somos totalmente determinados pela Natureza, porque também, como agentes dos atos de observação, participamos ativamente na sua determinação. Heisenberg referia-se claramente a um trecho de uma apresentação de Bohr em um congresso sobre Física e Biologia, ocorrido em Bolonha em 1937:

\begin{abstract}
Para um paralelo com a lição da teoria atômica acerca da limitada aplicabilidade dessas idealizações costumeiras, devemos nos voltar, na verdade, para ramos bem diferentes da ciência, como a psicologia, ou até para o tipo de problemas epistemológicos com que já se confrontavam pensadores como Buda e Lao Tsé, ao tentarem harmonizar nossas posições de espectadores e atores no grande drama da vida. (BOHR. 1995, p. 25-26)
\end{abstract}

Ao enfatizar que não somente em nível psicológico, mas como também no nível físico, no drama cósmico que se desenrola sobre o palco do mundo, além de criaturas somos também criadores da realidade, Heisenberg endossa a inseparabilidade entre homem e mundo, desatualizando a cisão cartesiana como fundamento lógicometodológico da ciência natural.

\title{
Considerações finais
}

Heisenberg foi um dos mais prolíficos físicos filósofos da primeira metade do século XX. Seu princípio de incerteza tornou-se um dos pilares da nova física, e sua mecânica matricial, junto com a mecânica ondulatória formulada por Schrödinger, é um dos fundamentos da mecânica quântica. Como filósofo, sua obra foi ainda mais extensa do que como físico. Escreveu centenas de páginas de reflexões sobre os problemas epistemológicos e lógicos das ciências naturais, e debruçou-se também sobre as relações entre ciência, sociedade, política, religião, arte e cultura. Foi, sem dúvida, um intelectual vasto e profundo. No entanto, talvez Heisenberg não tenha conseguido escapar a determinadas limitações e contradições. Ao negar as cisões cartesianas, ao que tudo indica, pode ter substituído as mesmas por uma nova separação ontológica, a saber, a diferença entre o macro e o micro, o clássico e o quântico. Como explicar essa passagem do emaranhado quântico de realidades potenciais superpostas aos objetos clássicos sem cindir a realidade em dois níveis? Embora tenha buscado até os seus últimos dias a unificação da física e a elaboração de uma imagem unificada e ordenada da natureza, o problema dos "dois mundos" pode não ter sido resolvido por sua epistemologia. No entanto, Heisenberg talvez ainda nos dissesse que entendemos errado, que não há cisão entre o quântico e o clássico, que ambos são manifestações diferentes, e complementares, da mesma realidade física. A separação não estaria na natureza, mas no sujeito que a investiga e interpreta. Seriam os resquícios do modo de pensar cartesiano atuando em nós?5

\footnotetext{
${ }^{5}$ Em termos físicos, Roland Omnès disse em seu Filosofia da ciência contemporânea que a resposta para tal enigma,
} 


\section{Referências}

BENJAMIM. C. Dicionário de biografias científicas. Rio de Janeiro: Contraponto, 2007.

BACHELARD, G. O novo espírito científico. Trad. Juvenal Hahne Jr., Lisboa: Edições $70,1996$.

BOHM, D; PEAT, D. Ciência, ordem e criatividade. Lisboa: Gradiva, 1989.

BOHR, N. Física atômica e conhecimento humano: ensaios 1932-1957. Trad. Vera Ribeiro. Rio de Janeiro: Contraponto, 1995.

BORN, M; AUGER; SCHRÖDINGER, E; HEISENBERG, W. Problemas da Física

Moderna. Trad. Gita. K. Guinsburg. São Paulo: Perspectiva: 2006.

CARUSO, F \& OGURI, V. Física moderna: origens clássicas e fundamentos quânticos. Rio de Janeiro: Editora Campus, 2006.

DAVIES, P. O enigma do tempo. Trad. Ivo Korytowski. Rio de Janeiro: Ediouro, 2000.

DESGarteS, R. Coleção Os Pensadores. J. Guinsburg e Bento Prado Júnior (Trad.). São Paulo Editora Nova Cultural, 1996.

EINSTEIN, A. Como eu vejo o mundo. Trad. H. P. de Andrade. Rio de Janeiro: Nova Fronteira, 1981.

- Sobre a teoria geral da gravitação: in Prêmios Nobel na Scientific American. São

Paulo: Duetto, 2010.

FEYNMAN, R. P. O que é uma lei física? Lisboa: Gradiva,1989.

FREGE, G. Os fundamentos da Aritmética, in Frege, Col. Os Pensadores. São Paulo: Nova Cultural, 1989.

GOMES, P. T. (As leis das estrelas) in Filosofia Especial. Ano I. Nº 3. São Paulo: Editora Escala, 2007.

HAWKING, S. Uma nova história do tempo. Trad. Vera de Paula Assis. Rio de Janeiro: Ediouro, 2005.

. O Universo numa casca de noz. Trad. Ivo Korytowski. São Paulo: Arx, 2001.

HEISENBERG, W. A parte e o todo: encontros e conversas sobre física, filosofia, religião e política. Rio de Janeiro: Contraponto, 1996.

. A Imagem da Natureza na Física Moderna. Lisboa: Livros do

Brasil, 1981.

. A ordenação da realidade: 1942. Tradução de Marco Antônio Casanova. Rio de

Janeiro: Forense Universitária, 2009.

. Física e filosofia. Brasília: Editora da Universidade de Brasília, 1987.

Más Allá de La Física. Madri: Editorial Católica, S. A., 1974.

. Nuclear Physics. London: Methuen \& CO. LTD.,1953.

a chamada decoerência quântica, foi dada somente na década de 1980. A decoerência explicaria como as interferências entre estados quânticos desapareceriam muito rapidamente no caso de objetos compostos por um grande número de partículas. A decoerência não seria uma fronteira entre dois mundos, mas um processo, por meio do qual os muitos estados quânticos se anulariam, com exceção do estado microscópio observado. A decoerência pode ser a expressão da unidade da natureza que Heisenberg vislumbrava. Se assim fosse, ao invés de uma nova cisão, teríamos uma ponte, ou melhor, uma fusão dos "dois mundos". 
- Páginas de reflexão e auto-retrato. Lisboa: Gradiva, 1990.

1952.

- Philosophic problems of nuclear science. New York: Philosophical Library,

OMNÈS, R. Filosofia da Ciência Contemporânea. Trad. Roberto Leal Ferreira. São Paulo: Editora UNESP, 1996.

PIZA, A.F.R.T. Schrödinger e Heisenberg: A física além do senso comum. São Paulo: Editora Odysseus, 2007.

SCHRÖDINGER, E. A Natureza e os Gregos: seguido de Ciência e humanismo. Lisboa. Edições 70, 1996.

- Mi concepción del mundo. Barcelona: Tusquets Editores, 1988.

1989.

. O que é a vida? Espírito e matéria. Trad. M. L. Pinheiro. Lisboa: Fragmentos,

SILVA, V. C. A interpretação filosófica da mecânica quântica de Werner Heisenberg:

Ontologia matemática e crise nos fundamentos da lógica clássica. Dissertação de

Mestrado. Rio de Janeiro: Universidade do Estado do Rio de Janeiro, 2012.

- O anti-realismo na filosofia da física de Werner Heisenberg: da potentia aristotélica ao formalismo puro. Griot, v. 3,n2, p. 109-120, 2011.

. Teoria quântica, Física Nuclear e Filosofia Grega. Griot : Revista de Filosofia v.15, n.1, junho/2017. pp. 2233-250.

VIDEIRA, A. A. P. Inevitabilidade da Filosofia na Ciência Natural do século 19. Ijuí: Editora Unijuí, 2013, p. 195).

. Filosofia da Ciência sob o signo dos Science Studies Abstracta, v.2, n.1, pp. $70-83,2005$.

. Historiografia e História da Ciência in Escritos: Revista da Casa de Rui Barbosa. Ano 1, n.1. 2007.

. Por que os físicos acreditam que as coisas existem? Breves comentários a respeito das relações entre ciência e metafísica. Braga: Axioma, 2017.

Autor(a) para correspondência: Vinícius Carvalho da Silva, Universidade Federal do Tocantins, Avenida NS 15, Quadra 109 Norte | Plano Diretor Norte CEP 77001-090, Palmas - TO, Brasil. carvalho.vinicius@mail.uft.edu.br 